\title{
On Brazilian Helobata Bergroth, 1888 (Coleoptera: Hydrophilidae) II: new distribution data
}

\author{
Bruno Clarkson ${ }^{1,2}$ \& Lúcia M. Almeida ${ }^{1,3}$ \\ 1 Universidade Federal do Paraná (UFPR), Departamento de Zoologia (DZ00), Laboratório de Sistemática e Bioecologia de Coleoptera (LSBC). \\ Curitiba, PR, Brasil. \\ 2 ORCID: 0000-0001-8999-6665. E-mail: brclarkson@gmail.com (corresponding author) \\ ${ }^{3}$ ORCID: 0000-0003-4277-711X. E-mail: lalmeida51@gmail.com
}

\begin{abstract}
As an add-on to the work of Clarkson et al. (2016), new distributional data on species of Helobata Bergroth, 1888 (Hydrophilidae: Acidocerinae) from Brazil is provided. Helobata amazonensis Clarkson, Santos \& Ferreira-Jr., 2016, is recorded for the first time for Roraima State and its female is recorded for the first time. Helobata quatipuru Fernández \& Bachmann, 1987 and H. Iarvalis (Horn, 1873) are recorded for the first time for Minas Gerais, Cerrado Biome area. The genus is recorded for the first time for Goiás State. Additions and modifications in the previously published key to Brazilian species are provided.
\end{abstract}

Key-Words. Acidocerinae; Amazon; Cerrado; Hydrophiloidea; Neotropical Region.

\section{INTRODUCTION}

The water scavenger beetle genus Helobata Bergroth, 1888 currently comprises thirteen species known from South America, reaching by one species - H. larvalis (Horn, 1873) - to Central and North America, and Caribbean (Clarkson et al., 2016; Short \& Fikáček, 2011). Helobata species are rare and found in small numbers in swamps and ponds. Hence, except for $H$. larvalis - widespread in the New World - many described species are known only by their holotype $(H$. amazonensis Clarkson et al., 2016, H. aschnakiranae Makhan, 2007, H. bitriangulata García, 2000, H. pantaneira Clarkson et al., 2016) or few specimens, and their known distributions are usually restricted to the type-locality or few localities (Clarkson et al., 2016).

On Helobata species occurring in Brazil, Clarkson et al. (2016) described two new species and provided a checklist and a key to the five species recorded from the country. The paper also provided new distribution data for all species, including a new record of $H$. quatipuru Fernández \& Bachmann, 1987, originally described from Pará State (Northern Brazil), for Rio de Janeiro State (Southeastern Brazil). The present paper is an add-on to Clarkson et al. (2016) and is based on the examination of the collection of the Museu de Zoologia in São Paulo (MZSP) where specimens of Helobata from Goiás (1 ex.), Mato Grosso do Sul (5 exs.), Minas Gerais (3 exs.) and Roraima (1 ex.) States in Brazil were found. Helobata amazonensis is recorded for the first time from Roraima, as well as $H$. larvalis and $H$. quatipuru for Minas Gerais, collected in a Cerrado Biome area. The genus is recorded for the first time in Goiás.

\section{MATERIALS AND METHODS}

All specimens were examined using a Zeiss Discovery V20 binocular stereomicroscope (150x). Measurements were taken using a Wild Heerbrugg M5-31261 binocular stereomicroscope (100x) with the aid of an ocular micrometer. Abdomen and male genitalia were dissected and cleared in $10 \% \mathrm{KOH}$ at $70^{\circ} \mathrm{C}$ for about 10 minutes, stored in a microvial pinned with the specimen. Each figure was composed of 15 to 25 photographs taken with a Leica M205C binocular microscope (100x) with an attached camera and aligned, stacked and combined using the Leica LAS EX software. The presented map was made using the software Google Earth Pro v7.3, edited in the software Adobe Illustrator vCS6. Geotagging was done based on the information in the labels of each examined specimens and available in the literature, the coordinates are approximate and may not correspond to the exact spot where the specimens were collected.

The terms applied for morphological features mainly followed Komarek (2004), with some terminology adapted from Lawrence et al. (2011), Fernández \& Bachmann (1987) and García (2000). Labels of the examined material are arranged in 
sequence from top to bottom, the data for each label are within double quotes (" "), a slash (/) separates the rows and double slashes (//) separate the labels. All examined specimens are deposited in the Museu de Zoologia, Universidade de São Paulo (MZSP), São Paulo, Brazil (S.A. Casari and C. Campaner).

\section{RESULTS}

\section{New distribution data}

\section{Helobata quatipuru Fernández \& Bachmann, 1987 (Figs. 1-6)}

Material examined: BRAZIL: Minas Gerais State: Arinos Municipality: "Arinos/ M. Gerais - Brasil/ 6-8.XI.1964/ Exp. Dep. Zool.// Helobata quatipuru/ Fernández \& Bachmann, 1987/ Clarkson det. 2018" (1 male: MZSP).

Distribution: Brazil (Fig. 12): Pará, Minas Gerais (new record) and Rio de Janeiro States.

Discussion: This species was described based on a single male from Quatipuru Municipality, Pará State coast, Northern Brazil, Amazon rainforest biome. Clarkson et al. (2016) recorded $H$. quatipuru from Atlantic rainforest area in Rio de Janeiro State, Southeastern Brazil, revealing an apparent disjunct distribution. The species is herein recorded for the first time from the Cerrado Biome (Brazilian savanna), based on the aforementioned specimen collected in northwestern Minas Gerais State (Southeastern Brazil). Cerrado sensu latu (Batalha, 2011) is localized between Amazon rainforest and Atlantic rainforest. The presence of the species in this biome may indicate a widespread continuous distribution of a rare and hard-to-find species.

The examined specimen is identified as $\mathrm{H}$. quatipuru mainly by the morphology of the male genitalia (Figs. 3-5) which has maximum width of phallobase at about half of its length; manubrium short and narrow, truncated at base; parameres longer than median lobe, inner margins sinuate in ventral view (Fig. 3), convex on basal half, concave on apical half, outer margins slightly convex, almost straight, apex slightly truncate, strongly bent inwards (Figs. 3-4); median lobe with shallow apical emargination on dorsal lobule (ca. $0.13 x$ the length of median lobe) (Fig. 4); ventral lobule as long as dorsal lobule, with apex visible on dorsal view, rounded, produced ventrally as a hook, visible in lateral view (Fig. 5); by the shape and morphology of head - anterior clypeal margin sinuous, anterolateral angles tooth-like produced (Figs. 1-2) and frontoclypeal suture inconspicuous (Fig. 1); and by the general morphology of the ventral projections - posteromedial elevation on mesoventrite semi-trapezoidal, very wide (1.60 x longer than wide), with strongly raised lateral carinae, oblique and converging anteriorly, widely distant, convex posteriorly, not strongly connected with the metaventral projection (Fig. 2); metaventral projection (between mesocoxae) forming an elevated longitudinal carina strongly connected with, somewhat higher than, metaventral medial carina (Fig. 2). Dorsal coloration - dark brown with black areas, head and pronotum without metallic sheen, pronotum with faintly delimited central black area, inconspicuous black spots around scutellum and some spots spread throughout elytral disc (Fig. 1), abdominal ventrites dark brown (Fig. 6); fine and very short, decumbent setae distributed on anterior half of the clypeus, and on lateral portions of frons; mouth parts - maxillary palpomere 3 and 4 subequal in length and mentum finely rugose on lateral portions (Fig. 2) and the punctures on elytral rows fine and irregularly spaced on row 10 also corroborate the identification.

The examined specimen (Figs. 1-6) shows variations in body length $-7.40 \mathrm{~mm}$ in length (remaining described species have 6.10 to $6.90 \mathrm{~mm}$ in length); on head microsculpture - clypeal disc and frons without distinct microsculpture on interstices of ground punctuation (shagreened in the specimens from Rio de Janeiro); punctures on elytra marked on rows 8-10 and striae 7-10 weakly marked (punctures weakly marked on rows 8-10 in the remaining described specimens). The general coloration of the specimen is slightly lighter than those examined in Clarkson et al. (2016). Based on the coloration of the ventral plates of thorax and abdomen we conclude this is a teneral specimen.

\section{Helobata amazonensis Clarkson, Santos \& Ferreira-Jr., 2016}

(Figs. 7-8)

Material examined: BRAZIL: Roraima State: Pacaraima Municipality: "Surumu, Roraima/ IX.1966/ M. Alvarenga \&/ F.M. Oliveira col.// Helobata amazonensis/ Clarkson et al., 2016/ Clarkson det. 2018" (1 female: MZSP).

Distribution: Brazil (Fig. 12): Amazonas and Roraima (new record) States.

Discussion: This species was described based on a single male specimen from Central Amazon. This is the first mention of a female specimen. The examined specimen corresponds to $H$. amazonensis by the moderate-size $5.00 \mathrm{~mm}$ in length compared to $5.70 \mathrm{~mm}$ in the holotype; the coloration - dorsum yellow with conspicuous brown areas, pronotum with well-defined central brown area, elytra with faint light brown spots close to humeral humps and diffusely spread throughout elytral disc (Fig. 7), and abdominal ventrites yellow (Fig. 8); the general morphology of head and mouth parts - anterior clypeal margin convex, slightly truncate medially (Figs. 7-8); frontoclypeal suture distinct (Fig. 7); maxillary palpomere 3 and 4 subequal in length (Fig. 8); mentum without conspicuous microsculpture; the general dorsal sculpture punctures on elytral rows fine, regularly spaced (Fig. 7); the presence of fine and very short decumbent setae distributed on anterior half of the clypeus; the general morphology of the ventral projections - posteromedial 
elevation on mesoventrite semi-trapezoidal, very wide, with strongly raised lateral carinae, oblique, widely distant each other, converging anteriorly; widely connected
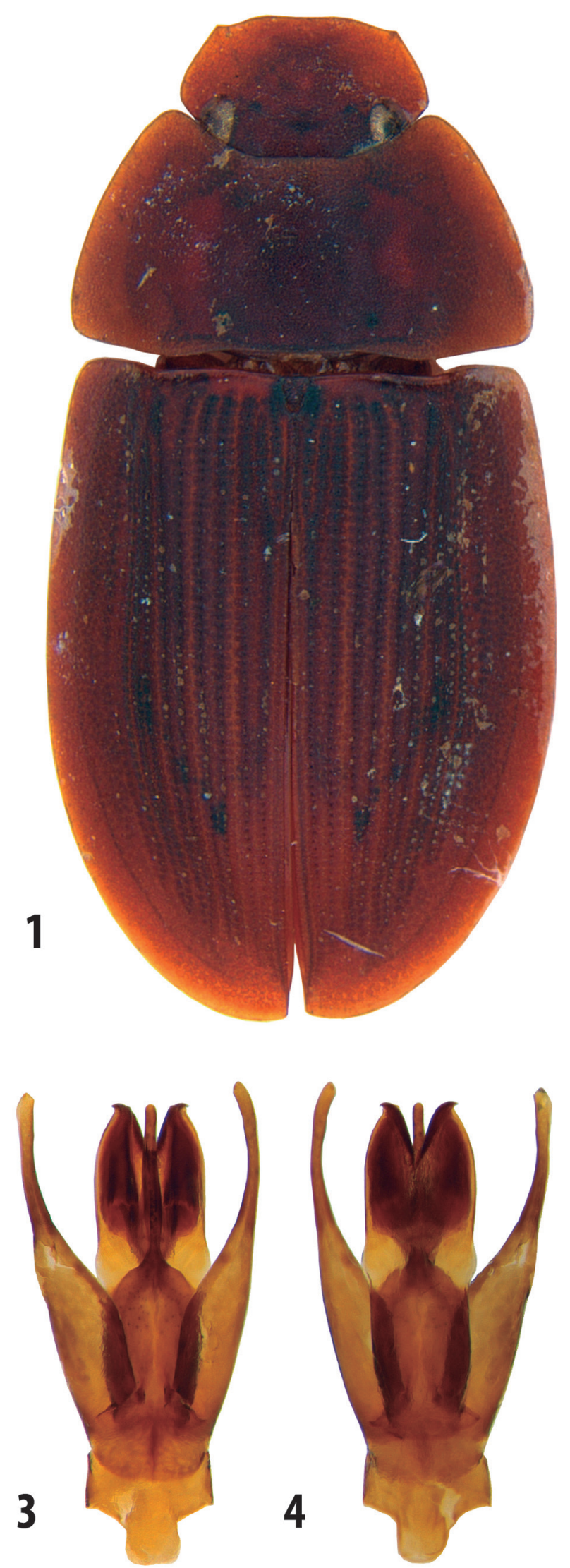

with the metaventral projection (Fig. 8); metaventral projection (between mesocoxae) forming an elevated longitudinal carina, strongly and widely connected posteri-
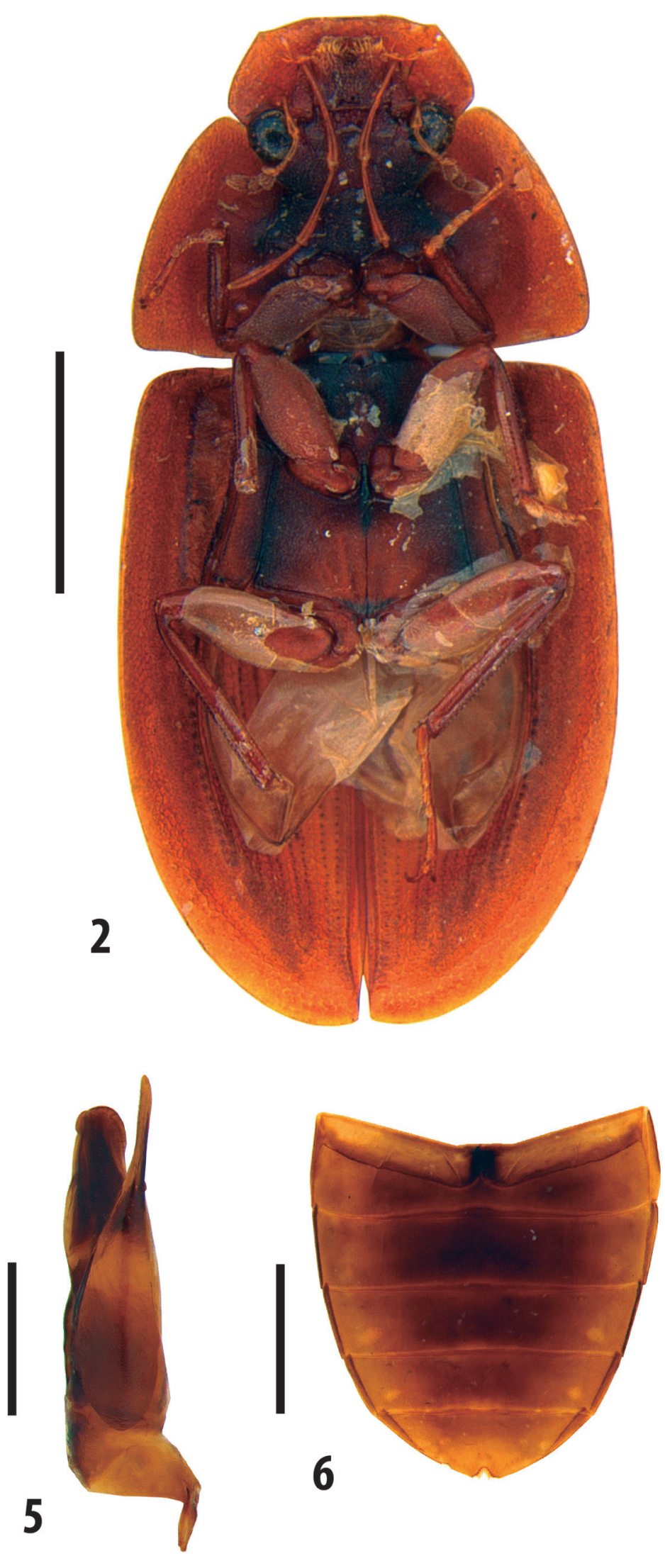

Figures 1-6. Helobata quatipuru Fernández \& Bachmann. Habitus, (1) dorsal view, (2) ventral view, scale $=2.0 \mathrm{~mm}$; aedeagus, (3) ventral view, (4) dorsal view, (5) lateral view, scale $=0.5 \mathrm{~mm}$; abdominal ventrites, (6) ventral view, scale $=1.0 \mathrm{~mm}$. 

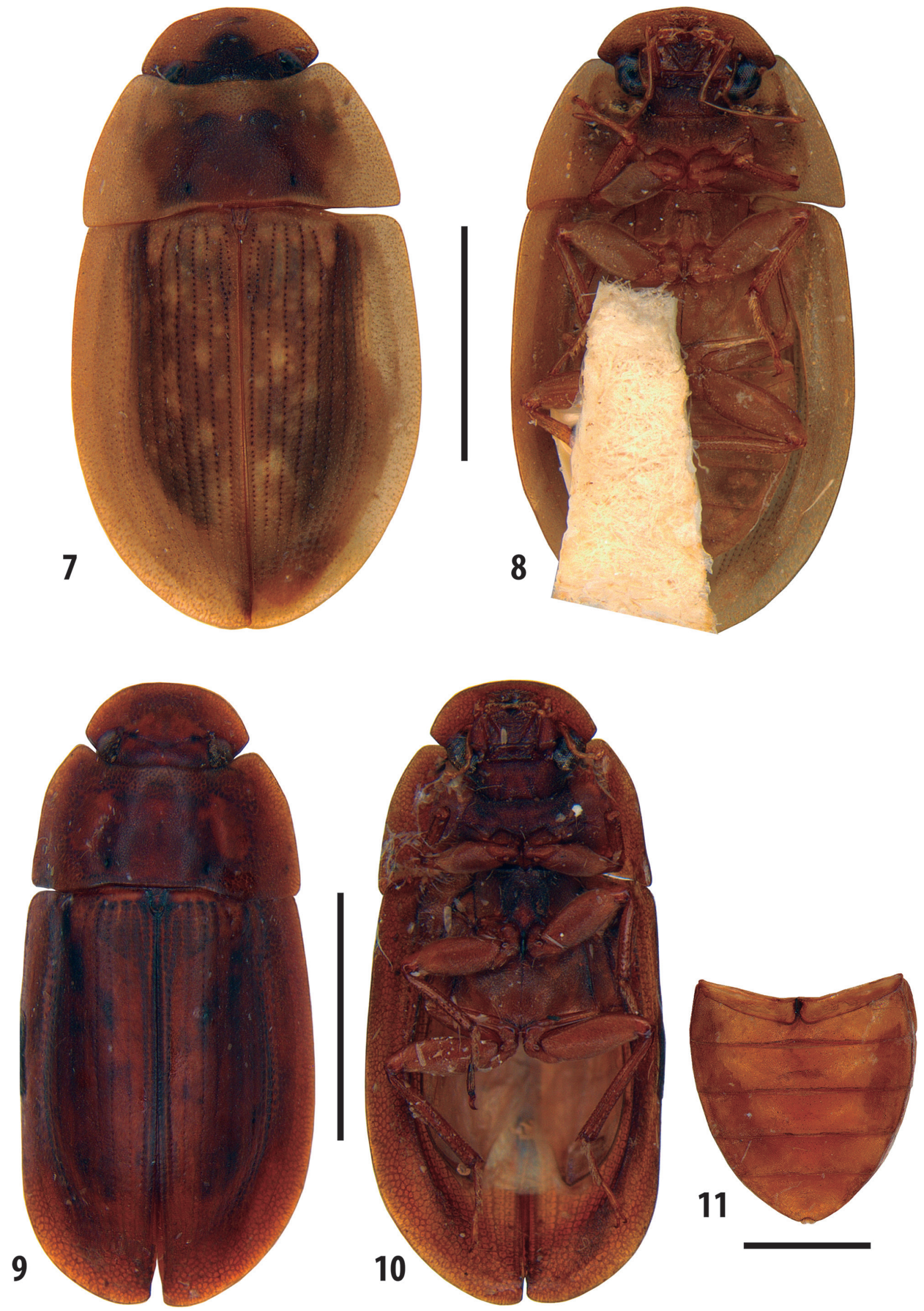

Figures 7-11. (7-8) Helobata amazonensis Clarkson, Santos \& Ferreira-Jr. Habitus, (7) dorsal view, (8) ventral view, scale = 2.0 mm; (9-11) Helobata sp. Habitus, (9) dorsal view, (10) ventral view, scale $=2.0 \mathrm{~mm}$; abdominal ventrites, (11) ventral view, scale $=1.0 \mathrm{~mm}$. 
orly with metaventral medial carina; metaventral medial carina rising gradually until connecting to metaventral projection (Fig. 8).

In comparison with the holotype the examined specimen (Fig. 7-8) shows variations in dorsal coloration as brown area on elytra expanded and elytral disc, head and pronotum without metallic sheen (with weak metallic sheen in the holotype); in the dorsal microsculpture as clypeal disc and frons with shagreened microsculpture on interstices of ground punctuation (without conspicuous microsculpture in the holotype); and in the presence of fine and very short decumbent setae on frons (absent in the holotype).

\section{Helobata larvalis (Horn, 1873)}

Material examined: BRAZIL: Mato Grosso do Sul State: Miranda Municipality: "Salobra, MT/ I.1955/ F.S. Pereira // Helobata larvalis/ (Horn, 1873)/ Clarkson det. 2018" (1 male, 4 unsexed specimens: MZSP); Minas Gerais State: Arinos municipality: "Arinos/ M. Gerais - Brasil/ 6-8. XI.1964/ Exp. Dep. Zool.// Helobata larvalis/ (Horn, 1873)/ Clarkson det. 2018" (2 females: MZSP).

Distribution: North America through the West Indies, Central America, and South America: USA, Mexico, Cuba, Guatemala, Venezuela, Bolivia, Paraguay, Argentina and Brazil (Fig. 12): Amazonas, Ceará, Mato Grosso, Mato Grosso do Sul and Minas Gerais (new record) States.

Discussion: This species is usually collected together with other species with more restricted distribution area. Records in Amazonas and Mato Grosso States published by Clarkson et al. (2016) were based on specimens collected with $H$. amazonensis, and with $H$. corumbaensis Fernández \& Bachmann, 1987 and H. pantaneira respectively. New records provided here are based on specimens collected together with the specimen of H. quatipuru in Minas Gerais State, presented above. See Fernández \& Bachmann (1987) and Clarkson et al. (2016) for diagnosis of the Brasilian specimens of $\mathrm{H}$. larvalis.

\section{Helobata sp.}

(Figs. 9-11)

Material examined: BRAZIL: Goiás State: Jataí Municipality: "Faz. Nova Orlandia/ Jataí, GO - Brasil/ I. 964 - Martins,/ Morgante \& Silva// Helobata sp./ Clarkson det. 2018" (1 female: MZSP).

Distribution: Brazil (Fig. 12): Goiás State, Center-West Region. This is the first mention of the genus in Goiás.

Discussion: Identification of Helobata species is usually based mainly on the shape of clypeus and general morphology of male genitalia since the external morphology of the species is similar (Fernández \& Bachmann, 1987). García (2000) and Clarkson et al. (2016) proposed rele-

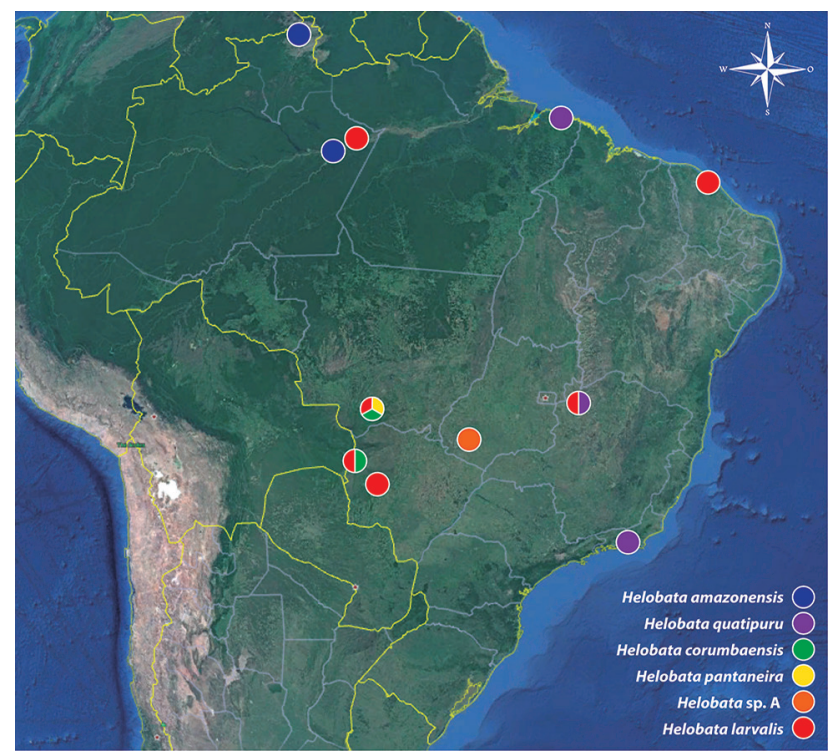

Figure 12. Updated distribution map of the Helobata Bergroth species in Brazil based on Fernández \& Bachmann (1987), Clarkson et al. (2016) and the current work.

vant external features for diagnosis and interspecific discernment (see Clarkson et al., 2016). The examined specimen is probably a new species and although we are here providing relevant features to diagnose it, we believe it is wiser to wait with formal description until male specimens are found. On the other hand, we are herein adding this morphotyped specimen in the previously published key to Brazilian species in order to help in the identification of the male when it is found.

The examined species is distinguishable from remaining described species by the combination of the following morphological features: shape narrowly oval (laterally constricted) (Figs. 9-10), moderate-sized species (5.25 mm in length); dorsum brown with black areas; head and pronotum without metallic sheen; pronotum with faintly delimited central dark brown area; with inconspicuous black spots around scutellum and some black spots spread throughout elytral disc (Fig. 9); abdominal ventrites brown (Fig. 11); clypeal disc and frons shagreened on interstices of ground punctuation; fine and very short, decumbent setae distributed on anterior half of the clypeus, and on lateral portions of frons; anterior clypeal margin largely convex (Figs. 9-10); frontoclypeal suture distinct (Fig. 9); maxillary palpomere 3 and 4 subequal in length; mentum finely rugose on lateral portions (Fig. 10); punctures on elytral rows fine, striae weakly marked, irregularly spaced on row 10 (Fig. 10). Posteromedial elevation on mesoventrite semi-trapezoidal, very wide (1.60x longer than wide), medial portion somewhat convex, with raised lateral carinae, oblique and converging anteriorly, widely distant, strongly connected with the metaventral projection (Fig. 10); metaventral projection (between mesocoxae) forming an elevated longitudinal carina, strongly and widely connected posteriorly with metaventral medial carina; metaventral medial carina rising gradually until connecting to metaventral projection (Fig. 10). 


\section{Key to the Helobata Bergroth of Brazil (adapted from Clarkson et al., 2016)}

A new step ( $\left(1^{\prime}\right)$ is herein added after couplet 1 , as well as modifications in both couplets 1 and 2, in order to incorporate Helobata sp. in the key, as follows:

1 Smaller species $(<6.0 \mathrm{~mm})$. Anterior clypeal margin convex sometimes slightly to conspicuously truncate medially, anterolateral margins rounded (e.g., Figs. 7-10 and Clarkson et al. (2016): figs. 1-2, 7-8 and 18-19). Median lobe of aedeagus with ventral lobule much shorter than dorsal lobule (male genitalia of Helobata sp. unknown) (e.g., Clarkson et al. (2016): figs. 4 and 10)

- Larger species (>6.0 mm). Anterior clypeal margin almost straight (e.g., Clarkson et al. (2016): figs. 12-13) or sinuous (e.g., Figs. 1-2 and Clarkson et al. (2016): figs. 20-21), anterolateral margins angulate (e.g., Figs. 1-2 and Clarkson et al. (2016): figs. 12-13, 20-21). Median lobe of aedeagus with ventral lobule as long as dorsal lobule (e.g., Figs. 3-5 and Clarkson et al. (2016): figs. 22-23) or at most slightly shorter (e.g., Clarkson et al. (2016): fig. 15) ..

$1^{\prime} \quad$ Posteromedial elevation on mesoventrite strongly connected with metaventral projection. Metaventral projection strongly connected posteriorly with metaventral medial carina (e.g., Fig. 10 and Clarkson et al. (2016): fig. 2); metaventral medial carina rises gradually until connecting to metaventral projection. Apex of paramere slightly truncate, strongly bent inwards; median lobe with shallow apical emargination on dorsal lobule; apex of ventral lobule strongly produced ventrally as a tooth, visible in lateral view (male genitalia of Helobata sp. unknown) (e.g., Clarkson et al. (2016): figs. 3-6) ....2

- Posteromedial elevation on mesoventrite not strongly connected with metaventral projection. Metaventral projection not strongly connected and abruptly higher than metaventral medial carina (e.g., Clarkson et al. (2016): figs. 8, 13, 19 and 21). Apex of paramere not truncate, not strongly bent inwards; median lobe with deep apical emargination on dorsal lobule; apex of ventral lobule at most weakly produced ventrally, not visible in lateral view (e.g., Clarkson et al. (2016): figs. 9-11)

2 Body shape widely oval in dorsal view (Figs. 7-8). Elytral punctures and striae distinctly marked. Punctures on $10^{\text {th }}$ elytral row regularly spaced (Fig. 7 and Clarkson et al. (2016): fig. 1). Metaventral projection widely connected posteriorly with metaventral medial carina (Fig. 8 and Clarkson et al. (2016): fig. 2) (Northern Brazil) ... Helobata amazonensis

- Body shape narrowly oval in dorsal view (laterally constricted) (Figs. 9-10). Elytral punctures shallow and elytral striae weakly marked. Punctures on $10^{\text {th }}$ elytral row irregularly spaced (Fig. 9). Metaventral projection narrowly connected posteriorly with metaventral medial carina (Fig. 10) (Center-Western Brazil) .............

Helobata sp.

3 Posteromedial elevation on mesoventrite with lateral carinae weakly raised. Metaventral projection forming a very narrow elevated longitudinal ridge (Clarkson et al. (2016): fig. 8). Parameres with inner margins slightly concave in ventral view, apices rounded; ventral lobule shorter than bottom of the emargination of dorsal lobule, not visible in dorsal view, apex weakly produced ventrally (Clarkson et al. (2016): figs. 9-11) Helobata pantaneira

- Posteromedial elevation on mesoventrite with lateral carinae strongly raised. Metaventral projection forming a flat elevated longitudinal carina (Clarkson et al. (2016): fig. 19). Parameres with inner margins

oblique on basal half, slightly concave on apical half in ventral view, apices slightly acuminated; ventral lobule longer than bottom of the emargination of dorsal lobule, visible in dorsal view, apex not produced ventrally (Fernández \& Bachmann (1987): figs. 5-7)......... Helobata larvalis

4

Anterior clypeal margin sinuous, anterolateral angles strongly produced, tooth-like (Clarkson et al. (2016): figs. 20-21); frontoclypeal suture indistinct (Clarkson et al. (2016): fig. 20). Metaventral projection strongly connected with, but somewhat higher than, metaventral medial carina (Clarkson et al. (2016): fig. 21); Median lobe of aedeagus with ventral lobule as long as dorsal lobule, apex produced ventrally as a hook (Clarkson et al. (2016): figs. 22-24) Helobata quatipuru

- Anterior clypeal margin weakly convex, almost straight, anterolateral angles weakly produced, obtuse (Clarkson et al. (2016): figs. 12-13); frontoclypeal suture distinct(Clarksonetal. (2016):fig. 12). Metaventral projection not strongly connected with, and conspicuously higher than, metaventral medial carina (Clarkson et al. (2016): fig. 13); Median lobe of aedeagus with ventral lobule somewhat shorter than dorsal lobule, apex very weakly produced ventrally, not hook-like (Clarkson et al. (2016): figs. 14-17) .................... Helobata corumbaensis

\section{ACKNOWLEDGEMENTS}

We would like to thank our colleges of the Laboratório de Sistemática e Bioecologia de Coleoptera for encouraging and supporting our work. We are indebted to Sonia A. Casari and Carlos Campaner (Museu de Zoologia, USP) to receive the first author in the collection and make the examined species available for this work. Financial support was provided by Programa Nacional de Pós Doutorado (CAPES, Brazil) granted by PPG em Entomologia (UFPR) to B. Clarkson.

\section{REFERENCES}

Batalha, M.A. 2011.0 cerrado não é um bioma. Biota Neotropica, 11(1): 1-4. Available at: www.redalyc.org/html/1991/199119839002. Access in: 16/03/2018

Clarkson, B.; Santos, A.D. \& Ferreira-Jr., N. 2016. On Brazilian Helobata Bergroth, 1888 (Coleoptera: Hydrophilidae): description of two new species, new records, and key to species. Zootaxa, 4126(4):548-562. D01

Fernández, L.A. \& Bachmann, A.0. 1987. Revisión del genero Helobata Bergroth (Coleoptera: Hydrophilidae). Revistadela Sociedad Entomológica Argentina, 45(1-5): 145-151.

García, M. 2000. Tres nuevas especies de Helobata Bergroth 1888 (Hydrophilidae: Hydrophilinae) de Venezuela. Boletín del Centro de Investigaciones Biológicas, 34(2): 237-246.

Komarek, A. 2004. Taxonomic Revision of Anacaena Thomson, 1859. I. Afrotropical Species (Coleoptera: Hydrophilidae). Koleopterologische Rundschau, 74: 303-349.

Lawrence, J.F.; Ślipiski, A.; Seago, A.E.; Thayer, M.K.; Newton, A.F. \& Marvaldi, A.E. 2011. Phylogeny of the Coleoptera based on morphological characters of adults and larvae. Annales Zoologici (Warszawa), 61: 1-217. D0I

Short, A.E.Z. \& Fikáček, M. 2011. World catalogue of the Hydrophiloidea (Coleoptera): additions and corrections II (2006-2010). Acta Entomologica Musei Nationalis Pragae, 51: 83-122. 